\title{
ADDITIONS TO THE NEARCTIC MELOIDAE (COLEOP.) ${ }^{1}$
}

\author{
By F. G. Werner \\ Harvard University and University of Vermont
}

Among specimens sent for determination by several institutions and collectors are three striking additions to our fauna, which are described below.

\section{Epicauta cicatrix sp. $n$.} Figure 5

This, the thirteenth member of the caviceps-group, is the only one of the group thus far known from the Big Bend region. It can be distinguished from the other members, and from all other Nearctic and Neotropical members of Epicauta, by the form of the second antennal segment (see fig. 5).

Length: 8 to $12 \mathrm{~mm}$. Black, moderately densely clothed with cinereous to yellow-cinereous pubescence, except for the black markings at the base of the elytra and on the abdomen which are characteristic of the group, and a partially denuded spot on the temporal angles of the head.

Head broad, $2 / 5$ broader across the eyes than from vertex to clypeus, tapering from just behind the eyes to the broadly rounded temporal angles. Surface moderately densely punctured and strongly microreticulate, appearing fairly shiny. Median impressed line narrowly denuded, distinct down to the level of the eyes. Antennal calluses small, denuded, shiny. Eyes prominent, slightly oblique but unmodified, $3 / 5$ as wide as high, as seen from side, with a narrow denuded zone surrounding them. Pubescence short on top of head, very short and fine, black on the patch on the temporal angles. Rest of head with rather coarse pubescence.

Antennae tapering gradually, with the intermediate segments stouter and the apical segments more slender in the $\hat{o}$ than in the ․ $f$ antennae slightly more than three times as long as anterior tibia; segment I stout, reaching $1 / 4$ across eye; II $2 / 3$ as long as I, posteriorly flattened and smooth, the base of the flattened area

${ }^{1}$ Published with a grant from the Museum of Comparative Zoology at Harvard College. 
with a transverse oval scar-like area, slightly elevated from the rest of the surface. This scar-like area has the surface roughened and with some very short erect hairs. Segment III $11 / 2$ times as long as I, almost circular in cross-section and slightly curved posteriorly; IV as long as I, almost tubular; rest decreasing gradually in thickness and almost imperceptibly in length; XI $2 / 3$ as wide as III, $1 / 3$ longer than $\mathrm{X}$. $q$ antennae $23 / 5$ as long as an anterior tibia; segment $I$ reaching to just beyond the margin of the eye, the rest bearing approximately the same proportion to $I$ as in the $\hat{\delta}$ but more slender basally and not tapering as much, so that XI is only $3 / 4$ as wide as III.

Pronotum quadrate, $1 / 10$ broader than long. Sides straight, diverging slightly from base to $1 / 3$ from apex, then forming a fairly sharp angle, converging abruptly to the collar, which projects forward slightly. Surface densely punctured and microreticulate. Disc elevated in the center into a low hump; from the central hump a set of more or less well-defined ridges project as follows: anteriorly a strongly elevated ridge, sometimes higher than the hump near its base; laterally a weak pair tending anteriorly and ending in a pair of feeble elevations on the edges of the disc; posteriorly a weak pair directed toward the posterior angles, leaving the middle of the base more or less excavated. Pubescence of disc confused, directed generally away from the central hump, toward the lateral elevations and often in a pair of whorls anteriorly.

Elytra with black scutellar markings extending across the base and forming a very weak humeral spot of a few hairs. Suture elevated on the basal $1 / 4$ and apical $1 / 3$. Underside with anterolateral black spots on sternites II to IV, sometimes also on $\mathrm{I}$ and $\mathrm{V}$, posterior midventral spots on II to IV, often on $V$ in the $\hat{o}$, reduced to one spot, on III, in one $q$. Middle and posterior trochanters and femora of $\hat{o}$ denuded behind, the denuded area having scattered short black hairs and margined above with long cinereous hairs; the femora slightly bowed, the middle femora more than the posterior. Posterior tibial spurs slender, sticklike.

Holotype: ô, Presidio, Texas, Nov. 14, 1944, J. H. Russell (USNM).

Allotype: $\$$, eutopotypical (USNM).

Paratypes: 27 eutopotypical, 3 topotypical, Nov. 6, 1944, 6 Nov. 8, 1947, 18 Nov. 27, 1948. Distributed in the USNM, MCZ, (No. 28502), in the collections of the author and F. H. Parker. All taken 
about a mile from Presidio, in the valley flat of the Rio Grande, on flowers and leaves of a yellow-flowered composite, Viguiera stenoloba.

\section{Lytta mirifica sp. $\mathrm{n}$.}

Figures 1,3

This is one of the most striking new species of Lytta to turn up in the United States since the revision of the genus by Fall. The type locality, Anthony, N.M., is in the Rio Grande valley, about ten miles north of El Paso, Texas. The species probably ranges over at least the adjacent area of Mexico but cannot be very widespread in the United States or it would certainly have been collected before.

Length: 16 to $25 \mathrm{~mm}$. Stout, black, with brick-red pronotum. Almost glabrous above, with some short, erect black pubescence below. Elytra coarsely reticulate, as in reticulata Say. Intermediate segments of $\hat{o}$ antennae somewhat lengthened and thickened. In Fall's key ${ }^{2}$ this species would go to Group I, near ulkei Horn. However, it is unique in our fauna in combination of color pattern and elytral reticulation.

Head subquadrate, 9/10 as long from vertex to clypeus as wide just behind the eyes, with scattered coarse punctures, fine punctulation and deep microreticulation, appearing roughened but somewhat shiny. Median impressed line distinct above, becoming weak or obsolete toward the clypeus. Eyes half as wide as high as seen from the side. Clypeus and labrum sculptured like head but with denser pubescence; labrum feebly emarginate.

$\delta$ antennae (fig. 1) half as long as body from vertex to tip of elytra, reaching basal fourth of the elytra. Intermediate segments elongate-moniliform, longer and stouter than in the $q$, particularly IV to VI. Segment I stout, reaching $1 / 4$ across the eye; II short, $3 / 8$ as long as I, strongly constricted at base, particularly externally; III $5 / 6$ as long as I, normal; IV $1 / 5$ longer than II, slightly swollen; $\mathrm{V}$ equal to IV or slightly longer, slightly thicker; VI to $\mathrm{X}$ decreasing slightly in length and thickness; XI 1/10 longer than $\mathrm{I}$ and slightly thicker than $\mathrm{X}$.

$q$ with first antennal segment stout, twice as long as broad and reaching $1 / 4$ across eye; II short, $3 / 8$ as long as $I$ and constricted as in $\hat{\delta}$; III $3 / 4$ as long as I and $4 / 5$ as thick; IV $9 / 10$ as long as I; $\mathrm{V}$ to VII decreasing in length; VII to $\mathrm{X}$ approximately equal, $1 / 3$ as long as I; III to XI gradually increasing in thickness, $\mathrm{X}$ being

${ }^{2}$ Fall, H. C., 1901, Trans Am. Ent. Soc. 27:295. 
1/3 thicker than III; XI stout, slightly thicker and almost $4 / 5$ longer than $\mathrm{X}$.

Pronotum 1/10 broader than long, hexagonal, angulate at the sides just before the middle, with scattered coarse punctures, fine punctulation and shallow microreticulation, appearing smooth and feebly shiny. Disc flattened, with a feeble median impressed line, a pair of feeble impressions laterally behind the middle and one in the center of the base. Basal impressed line distinct.

Elytra coarsely reticulate, with the ridges of the reticulations narrow. The entire surface is punctulate and microreticulate, appearing dull and roughened. Underside entirely black, more densely punctured and pubescent than above. Anterior tibiae with two slender apical spurs in both sexes. Middle tibiae bowed; posterior tibiae slightly bowed, with the inner apical spur slightly broadened, the outer broad and longer, both obliquely excavated. $\hat{\sigma}$ with the sixth abdominal sternite with a V-shaped notch which extends forward as a feeble groove; pygidium normal, rounded apically; aedeagus (fig. 3) flattened, with two recurved spines.

Holotype: ô, Anthony, New Mexico, June 21, 1941, R. H. Crandall (MCZ No. 28500).

Allotype: $ᄋ$, eutopotypical (MCZ).

Paratypes: 20 ô $\hat{o}, 11$ 우 topotypical, May 23 to July 15, 1941, R. H. Crandall. In the collections of Cornell University, F. H. Parker and the author.

\section{Lytta navajo sp. $n$.}

Figures 2,4

Length: 16 to $23 \mathrm{~mm}$. Moderately stout, deep blue-black except for a small orange frontal spot on the head, semi-opaque and with the elytra scabrous. In Fall's key (footnote 2) this species runs to Group II, couplet 1, but differs from all of the species listed there in being all blue-black, having the elytra scabrous and the metatrochanters of the $\delta$ not spinose. Entire surface deeply microreticulate, appearing dull. Head and pronotum with some short, erect pubescence; elytra almost glabrous; underside with slightly longer pubescence than head and pronotum.

Head triangular, widest at the temporal angles, 1/5 broader than long, with dense, moderately deep but small punctures, somewhat uneven on the disc. Median impressed line distinct down to the level of the hind margin of the eyes. Eyes slightly more than 
half as wide as high as seen from side. Clypeus with a broad transverse basal impression, and with sculpture like head; labrum smoother, feebly emarginate.

of antennae (fig. 2) 2/5 as long as body from vertex to tip of elytra, almost the same as in the $q$, becoming gradually stouter apically. Segment I moderately stout, reaching $1 / 3$ across eye, with the apex oblique; II short, $3 / 8$ as long as I; III 9/10 as long as I; IV to $\mathrm{X}$ subequal to III in length, becoming moniliform: XI $2 / 5$ longer than I, sharply pointed. The antennae of the $q$ are essentially like those of the $\hat{\delta}$.

Pronotum $1 / 7$ broader than long, about as wide as head, flattened and roughened on the disc, widest at apical third. Sculpture similar
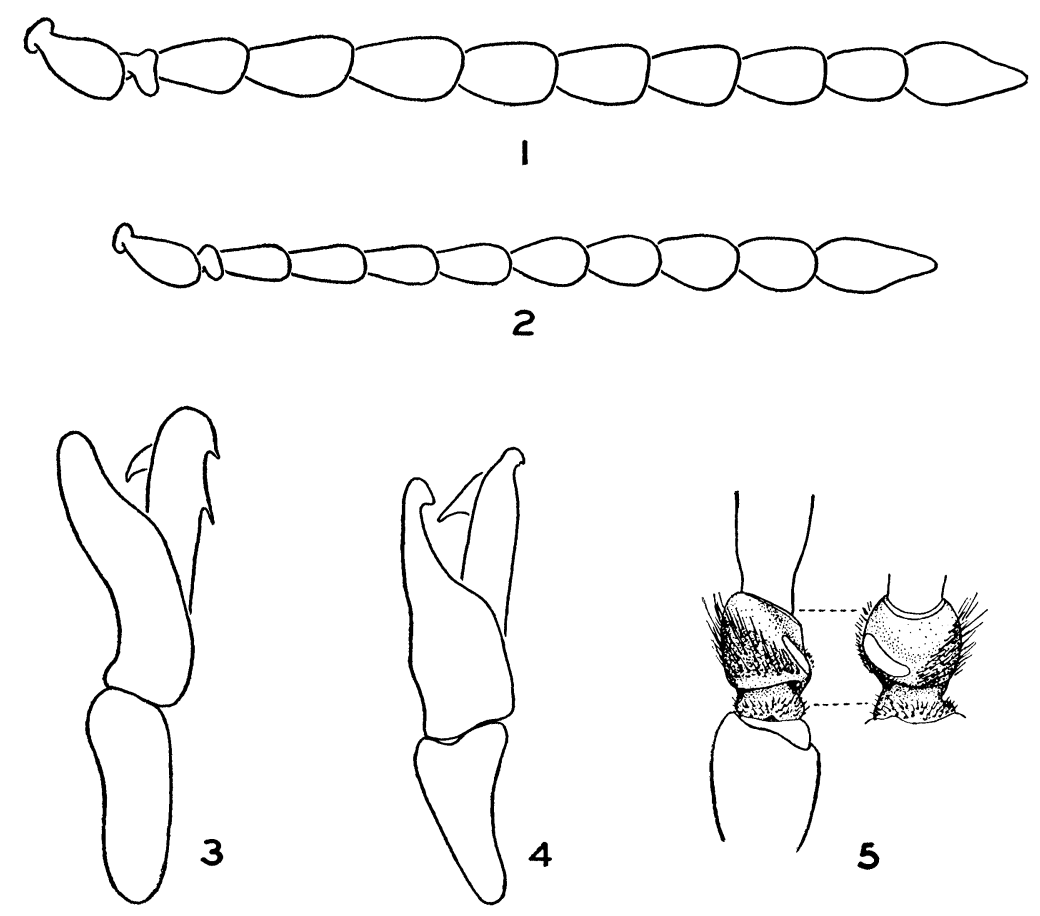

Figs. 1-5. Fig. 1. Lytta mirifica sp. n., $\hat{\text {, }}$, right antenna. Fig. 2 Lytta

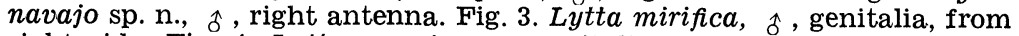
right side. Fig. 4. Lytta navajo, $\hat{s}$, genitalia, from right side. Fig. 5. Epicauta cicatrix sp. n., second segment of right antenna, dorsal and posterior views. 
to head except toward middle of disc, which is smoother. Base with a strong transverse impression. Median impressed line feeble.

Elytra coarsely scabrous, with very feeble costulae, one near the margin, another arising one third of the way from the humeri to the suture and a third arising near the scutellum. Legs stout, with the tibiae flattened, the middle and posterior tibiae bowed in both sexes. Outer spur of the posterior tibiae broad, the inner slender. $\hat{o}$ with sixth abdominal sternite deeply and sharply notched, fifth broadly and feebly notched; aedeagus (fig. 4) constricted near apex, and with a small double recurved spine.

Holotype: ô, $22 \mathrm{mi}$. N. of Cameron, Coconino Co., Arizona, May 19, 1949, H. Epson, feeding on Astragalus. (MCZ No. 28501).

Allotype: $\&$, eutopotypical (MCZ).

Paratypes: 1 of, 2 $q$, eutopotypical, in the collections of the University of Wyoming, F. H. Parker and the author. 

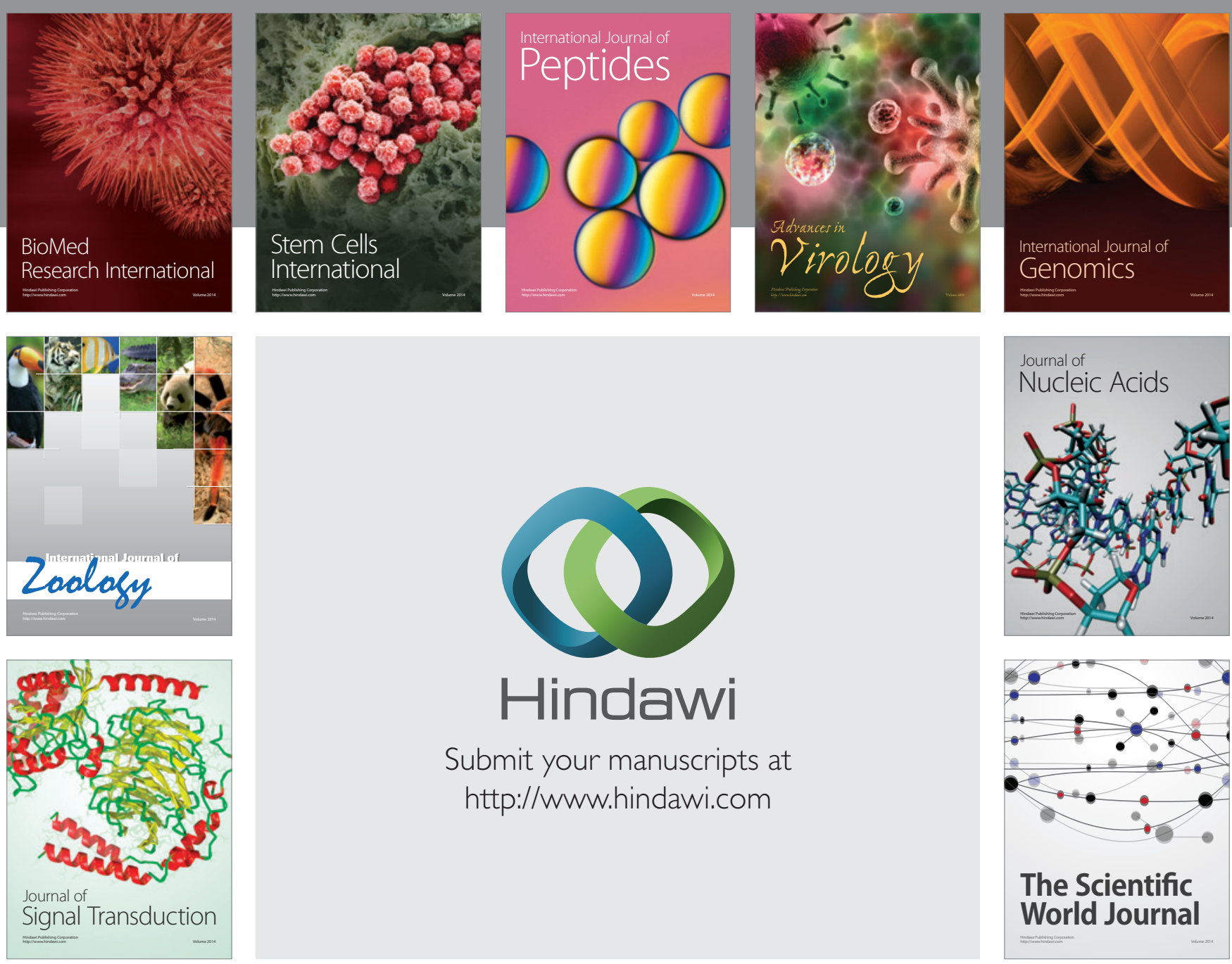

Submit your manuscripts at

http://www.hindawi.com
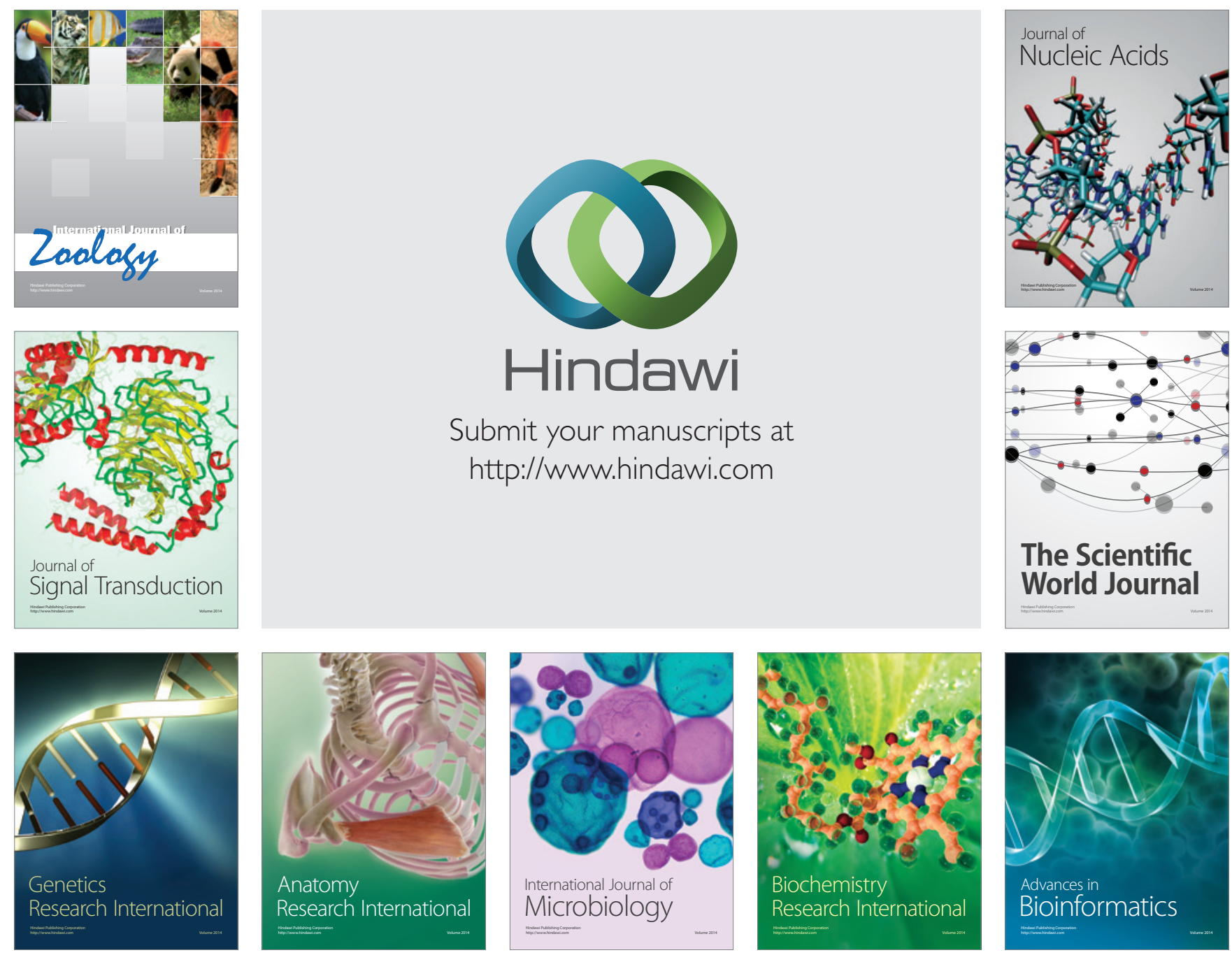

The Scientific World Journal
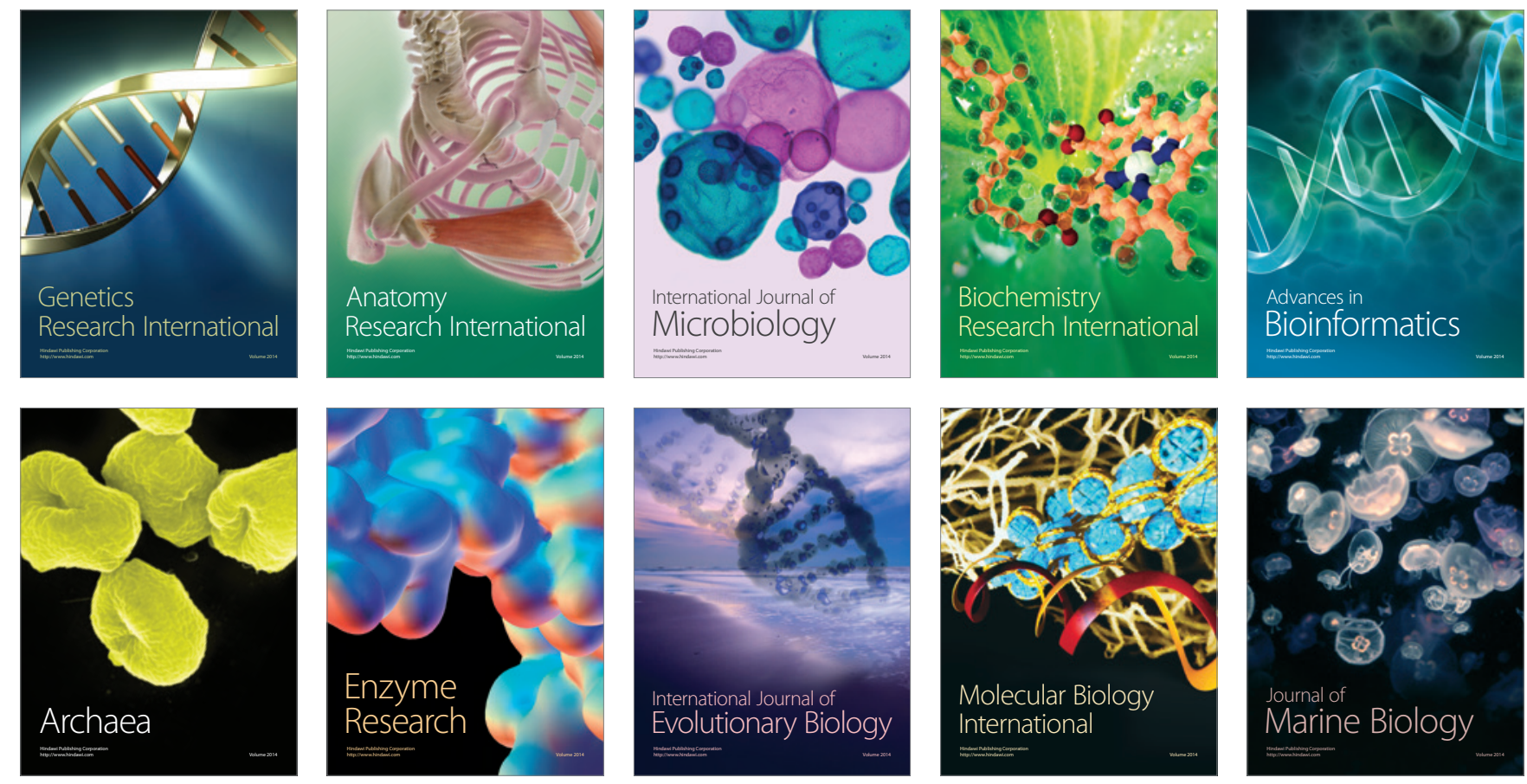